\title{
Is it possible to measure the impact of a developmental disorder diagnosis received in adulthood? An attempt at follow-up and discussion of difficulties encountered in the process
}

This article was published in the following Dove Press journal:

Clinical Audit

24 November 2010

Number of times this article has been viewed

\author{
Lena Nylander ${ }^{1,2}$ \\ Maria Holmqvist' \\ Sven Jönsson' \\ Lars Gustafson ${ }^{3}$ \\ Christopher Gillberg ${ }^{2}$ \\ 'Department of Psychiatry, Clinical \\ Sciences, Lund University, Lund, \\ Sweden; ${ }^{2}$ Child and Adolescent \\ Psychiatry, Institute of Neuroscience \\ and Physiology, Göteborg University, \\ Göteborg, Sweden; ${ }^{3}$ Department of \\ Geriatric Psychiatry, Clinical Sciences, \\ Lund University, Lund, Sweden
}

Objective: Assessment of patients' and their significant others' (SOs') views of receiving a diagnosis of a developmental disorder, namely attention-deficit/hyperactivity disorder (ADHD), autism spectrum disorder (ASD), or Tourette's syndrome (TS), in adulthood.

Method: One to three years after clinical examination and diagnosis, a questionnaire was sent to 225 consecutive patients.

Results: One hundred twenty-one patients responded (53.7\%). The number of ASD patients in contact with habilitation services and with independent living had increased, as also had the number of ADHD patients receiving medication. The patients and SO expressed satisfaction with the diagnostic process.

Conclusion: ADHD or ASD diagnoses received in adulthood did not, in the patients' opinion, have a great impact in a 1- to 3 -year perspective. However, since a large number of the responding patients as well as SOs were positive to the examination as such, it is suggested that the so-called neuropsychiatric diagnostic procedure may lead to rapport and thus understanding of psychiatric patients, irrespective of diagnosis. The low number of respondents is an indication that mailed questionnaires may not be the optimal method to follow-up the impact of the developmental disorder diagnosis in these patients. There are also difficulties regarding the choice of a relevant control group and regarding measurement of patients' opinions.

Significant outcomes: According to the patients themselves, rather small changes were brought about by receiving an ADHD or ASD diagnosis in adulthood. Patients who were assigned an ADHD or ASD diagnosis were more satisfied with the diagnostic procedure and its consequences than the reference group, consisting of patients who were examined, but did not meet the criteria for an ADHD, ASD, or TS diagnosis. Patients and SOs had a positive view of the assessment procedure.

Limitations: Forty-six percent of the included patients did not respond. The reference group was a diagnostically heterogeneous group of patients, most of whom had severe mental disorders. The availability of services may be a confounding factor, influencing the patients' views of the present situation and the benefit of the diagnosis. There was no questionnaire given to the patients at baseline, and the mailed questionnaire had not been validated. Considering that every patient or SO answered several questions, the differences at $P=0.05$ may not actually be significant if corrected for multiple comparisons.

Keywords: attention-deficit/hyperactivity disorder, autism spectrum disorder, adults, assessment, follow-up
Correspondence: Lena Nylander Department of Psychiatry, Clinical Sciences, Lund University, Autismmottagningen, MC S:t Lars I tr korr A, 22I85 Lund, Sweden

$\mathrm{Tel}+4646174270$

Fax +46462110923

Email lena.nylander@skane.se submit your manuscrip

Dovepress

DOI: $10.2147 /$ CA.SI394| 


\section{Introduction}

The adult features of certain developmental disorders particularly attention-deficit/hyperactivity disorder (ADHD), autism spectrum disorders (ASD), and, to some extent, Tourette's syndrome (TS) - have been elucidated in several studies in recent years. These studies have often been based on longitudinal follow-up of the course and description of outcome in young adult age of cases diagnosed in childhood.

As for ADHD, it is now well established that symptoms and/or impairment in a substantial group of affected children will persist into adulthood. ${ }^{1-5}$ Psychiatric syndromes, such as antisocial personality disorder, mood and anxiety disorders, and substance/alcohol dependence, often emerge in these patients from adolescence onward. ${ }^{6,7}$ Social, educational, and occupational performance is very often compromised in these individuals. ${ }^{2,3,8}$ Against this background, it is not surprising that $\mathrm{ADHD}$ is now increasingly diagnosed in adults who seek psychiatric services and/or who have substance/ alcohol dependence problems. ${ }^{9-13}$

For patients diagnosed with autistic disorder in childhood, outcome in adulthood has been generally described as gloomy. ${ }^{14-17}$ However, as the concept of the autism spectrum has evolved, less severely impaired cases have been included in the studied patient cohorts. Studies including more high-functioning ASD patients have revealed that the outcome of around one-third, or even more, can be described as 'fair' or 'good'. ${ }^{17-20}$ Adults with ASD seem to be at risk for severe motor disorder ${ }^{21}$ and psychiatric illness. $^{22-24}$

As diagnostic criteria have been broadened to include spectrum disorders, ${ }^{25}$ interest has grown regarding the possibility to diagnose also ASD in adult individuals. A few studies of the frequency of ADHD and ASD in groups of adult psychiatric patients have been done, pointing to the possibility that many patients treated under other diagnostic labels have persistent $\mathrm{ADHD}^{8,9}$ or, albeit to a lesser extent, ASD as an underlying disorder, ${ }^{26}$ but that these developmental disorders often have not been recognized in adult psychiatry.

When adult patients are examined for disorders that have been persisting from early childhood, family members or significant others (SOs) usually, if possible, are involved in the diagnostic procedure. Individuals with ADHD or ASD often seem to be more dependent on their families well into adulthood than persons without developmental disorders. Several studies have pointed out the burden of caregivers of children with ADHD or ASD, ${ }^{27-31}$ but to our knowledge, no studies have been performed of the family burden caused by these disorders in adults.

Since it has been assumed that adults with undiagnosed ADHD, ASD, or TS would benefit from a well-substantiated diagnosis and that diagnosis would lead to more effective treatment and better services offered, diagnostic services for persisting developmental disorders in adult patients have been established in many psychiatric clinics. However, so far little is known about whether or not the diagnosis of ADHD or ASD leads to any positive changes in the daily life for the affected adult. In one Swedish study comprising 20 adults with ADHD or ASD completing a questionnaire at least 1 year after diagnosis,${ }^{32}$ it was concluded that these patients had considerable but unmet needs for support. Getting a diagnostic label indicating a developmental disorder may not be uncontroversial for the patient; a negative bias against the ADHD diagnosis has been found among college students, ${ }^{33}$ and in two small studies, some of the patients with diagnosed ASD were negative to or felt stigmatized by this label. ${ }^{34,35}$

\section{Aims}

This study is an effort to assess effects of a neuropsychiatric examination and an ADHD, ASD, or TS diagnosis on the further treatment and social adaptation of adult patients, testing the hypothesis that a diagnosis of any of these disorders would lead to positive changes and be of greater benefit to the patient than not getting any of these diagnostic labels. We wanted to explore how patients experienced receiving a diagnosis which often 'explained' many years of adaptive difficulties. Since several of the patients were dependent on support from their families and since family members often were involved in the diagnostic procedure, we were also interested in whether SOs were satisfied with the result of the assessment.

\section{Research ethics}

The study was approved by the Committee for Research Ethics, Faculty of Medicine, University of Lund. The patients were informed about the aims and methods of the study by letter, and they signed a written consent to participate.

\section{Material and methods}

The Neuropsychiatric Diagnostic Team (NDT) for adults in Lund was established in 1998 as part of the adult psychiatric clinic at the University Hospital of Lund, Sweden. The team's remit was to diagnose or exclude ADHD, ASD, or TS in adults where this question had been raised. The staff 
consisted of one psychiatrist and one neuropsychologist, both with expert knowledge of ADHD and ASD. The diagnostic procedure of the NDT was clinically orientated and adapted to the individual cases, always including extensive history-taking and clinical assessment by both professionals. In most cases, neuropsychological testing (77.5\%) and collateral interviews (78.4\%) were performed. As a final step in the diagnostic procedure, test results, clinical impressions, and diagnostic considerations were discussed with the patient. Consensus on the description of development and functioning and thus on diagnosis was generally achieved.

Diagnostic and Statistical Manual of Mental Disorders, Fourth Edition (DSM-IV) diagnostic criteria ${ }^{25}$ for ADHD, TS, and ASD (autistic disorder, Asperger's syndrome, and pervasive developmental disorder-not otherwise specified) were used, except in the case of Asperger's syndrome for which Gillberg and Gillberg's criteria ${ }^{36}$ were used. Cases meeting criteria both for Gillberg and Gillberg's Asperger's syndrome and autistic disorder were assigned the latter diagnosis. One of four main diagnostic group categories was arrived at in all cases: no diagnosis of ADHD, ASD, or TS, or ADHD, ASD, or TS, respectively, as main diagnosis.

After assessment and diagnosis, the patients were referred back to their referring clinics (mostly adult psychiatry or general practice) or to the habilitation services.

The follow-up study comprised 231 patients, 141 (61\%) men and 90 (39\%) women, consecutively seen by the NDT from the start until August 31, 2001. Patient age range was 18-60 (mean 31.4) years at the time of assessment by the NDT. A majority (90\%) of the patients had been previously treated in child and/or adult psychiatry and $70 \%$ had been diagnosed with psychiatric or developmental disorders $(16.5 \%)$, the latter mostly mental retardation. Four cases had childhood diagnoses of ASD which were confirmed. Fourteen cases with childhood diagnoses of ADHD or similar disorders were diagnosed as ADHD in eight cases and ASD in four cases while two cases were not found to meet criteria for ADHD or ASD. One patient with a former TS diagnosis was diagnosed with comorbid ADHD.

Eighty-five patients had been found by the NDT to meet criteria for ADHD and 63 for ASD. Two patients had only TS, while three patients with ADHD and two with ASD had TS as a comorbidity. Among the patients with ADHD, none met criteria for any ASD. In the ASD group, some patients had attention problems, but none in this group met full criteria for ADHD. In 81 (35\%) patients, a diagnosis of ADHD, ASD, or TS had not been confirmed.
The latter group is used as reference group in the follow-up study, since the aim was to investigate the impact only of the confirmed ADHD, ASD, or TS diagnosis.

For the follow-up study, one questionnaire containing 32 questions for patients ${ }^{37}$ and one with 21 questions for $\mathrm{SOs}^{38}$ were constructed. Some questions concerning work, housing, economy, and treatment were formulated to compare with baseline data collected at assessment. Other questions concerned satisfaction with the diagnostic evaluation and with different aspects of life circumstances after diagnosis and was rated on a scale from 1 (not at all) to 5 (totally). The patients were asked to perform a self-assessment, and the SOs were asked to assess the patient using the Global Assessment of Functioning (GAF) scale. ${ }^{25}$ The questionnaires were completed anonymously, using code numbers, and collected by a researcher (SJ) who had not been involved in the diagnostic assessment.

The questionnaires were distributed by mail to all patients who were alive and had a registered address $(n=225)$. The patients were contacted 12-44 months after the neuropsychiatric assessment. The SO questionnaires were sent out only after obtaining the patients' written permission for contact. See Figure 1 for study design and procedure.

\section{Statistical methods}

$P<0.05$ was used as a minimum significance level in comparisons of results between groups. SPSS (version 15.0; SPSS Inc., Chicago, IL) independent samples $t$-test was used.

\section{Results}

At follow-up, four patients, all male, had died at the age of 25-43 years. Three of these (one with ASD and two in the 'no new diagnosis' group) had committed suicide by violent means. The fourth person, who had ADHD and TS, died from intoxication. In this case, suicide was not confirmed.

\section{Response and nonresponse}

Two individuals had moved abroad and left no forwarding addresses. Thus, the questionnaire was distributed to 225 persons of whom 121 (53.7\%) responded. Response frequency varied between the diagnostic groups, with $42 \%$ in the 'no new diagnosis' group and $66 \%$ in the ASD group $(P<0.001)$. Of the responders, 85 patients $(70.2 \%)$ allowed contact with a named SO (in one case, two persons). A questionnaire was thus sent to $86 \mathrm{SOs}$, and SOs of 60 patients ( $27 \%$ of the $225 ; 70 \%$ of those contacted) responded. Age range, gender, cognitive level, and anamnestic alcohol and/ or substance dependence/abuse of the patient group and of 


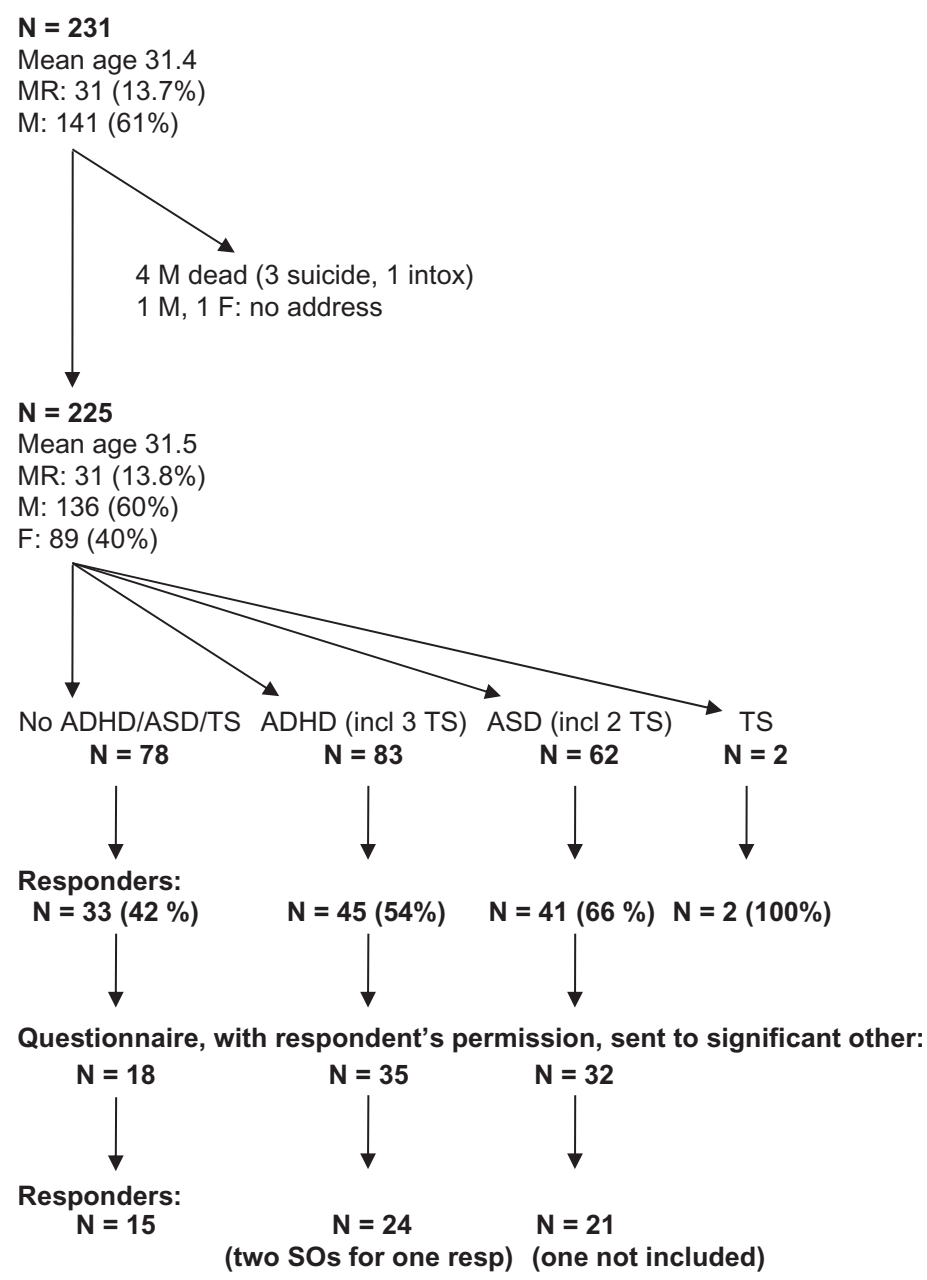

Figure I Study design.

Abbreviations: ADHD, attention-deficit/hyperactivity disorder; ASD, autistic spectrum disorder; TS, Tourette's syndrome; MR, mental retardation; SO, significant other.

Table I Characteristics of eligible patients $(n=225)$ : age, gender, MR, and S/A abuse

\begin{tabular}{|c|c|c|c|c|c|}
\hline \multirow[t]{2}{*}{ Diagnosis } & \multirow[t]{2}{*}{ ADHD } & \multirow[t]{2}{*}{ ASD } & \multirow[t]{2}{*}{ TS } & No & Total \\
\hline & & & & \multicolumn{2}{|l|}{ ADHD/ASD/TS } \\
\hline $\mathrm{n}$ & 83 & 62 & 2 & 78 & 225 \\
\hline Age, mean (SD) & $32.3(9.3)$ & $30.4(9.8)$ & $27.5(3.5)$ & $31.6(11.4)$ & $31.5(10.2)$ \\
\hline Male, n (\%) & $47(57)$ & $43(69)$ & $2(100)$ & $44(57)$ & $136(60)$ \\
\hline Female, n (\%) & $36(43)$ & $19(31)$ & 0 & $34(43)$ & $89(40)$ \\
\hline MR, n (\%) & $10(12)$ & $15(24)$ & 0 & $6(7.7)$ & $31(13.8)$ \\
\hline S/A abuse, $n$ (\%) & $33(39.8)$ & $2(3.2)$ & I (50.0) & $8(10.3)$ & $44(19.6)$ \\
\hline
\end{tabular}

Abbreviations: ADHD, attention-deficit/hyperactivity disorder; ASD, autistic spectrum disorder; MR, mental retardation; S/A abuse, substance and/or alcohol abuse; TS, Tourette's syndrome.

Table 2 Characteristics of responders $(n=121)$ : age, gender, MR, S/A abuse, mean follow-up time (months)

\begin{tabular}{llllll}
\hline Diagnosis & ADHD & ASD & TS & No \\
ADHD/ASD/TS
\end{tabular}

Abbreviations: ADHD, attention-deficit/hyperactivity disorder; ASD, autistic spectrum disorder; MR, mental retardation; S/A abuse, substance and/or alcohol abuse; SD, standard deviation; TS, Tourette's syndrome. 
Table 3 Characteristics of patients and SO

\begin{tabular}{|c|c|c|c|c|}
\hline Diagnosis & No ADHD/ASD/TS & ADHD & ASD & Total \\
\hline $\mathrm{n}$ & 11 & 28 & 20 & 59 \\
\hline Age, mean (SD) & $31.4(10.4)$ & $31.0(7.4)$ & $31.7(10.8)$ & $31.2(9.0)$ \\
\hline Male, n (\%) & $5(45.5)$ & $15(53.6)$ & $13(65.0)$ & $33(55.9)$ \\
\hline Female, n (\%) & $6(54.5)$ & $13(46.4)$ & $7(35.0)$ & $26(44.1)$ \\
\hline MR, n (\%) & $2(18.2)$ & $6(21.4)$ & $5(25.0)$ & $13(22.0)$ \\
\hline S/A abuse, $n(\%)$ & 0 & $12(42.9)$ & 0 & $12(20.3)$ \\
\hline Follow-up time & 30.6 & 29.7 & 29.0 & 29.7 \\
\hline Neuropsych tested, $\mathrm{n}^{\prime}$ & 7 & 26 & 19 & 52 \\
\hline Collateral interview, $\mathrm{n}^{2}$ & 10 & 24 & 18 & 52 \\
\hline P: usefulness; ${ }^{3}$ mean $(n)$ & $3.22(9)$ & $4.07(28)$ & $4.39(18)^{*}$ & - \\
\hline P: pos change; ${ }^{4}$ mean $(n)$ & $2.27(\mathrm{II})$ & $3.15(27)$ & $3.56(18)^{*}$ & - \\
\hline SOs/parents & 10 & 17 & 16 & 43 \\
\hline SOs/siblings & 1 & I & 1 & 3 \\
\hline SOs/partners & 0 & 10 & 1 & 11 \\
\hline SOs/other & 0 & I & 2 & 3 \\
\hline SOs/total & 11 & $29^{5}$ & 20 & 60 \\
\hline
\end{tabular}

Notes: Diagnostic groups, age, gender, MR, S/A abuse, mean follow-up time (months) of patients; neuropsychological testings and collateral interviews performed; patients' opinions on usefulness and positive change after evaluation/diagnosis; characteristics of SO. 'Neuropsychological testing performed by the NDT (two were never tested, and five had been tested before the NDT evaluation); ${ }^{2}$ Collateral interview performed by the NDT; (In 7 cases, this had not been possible at the time of the evaluation.); ${ }^{3} \mathrm{P}$ : usefulness indicates patients' opinions on usefulness of evaluation/diagnosis, scale I (not at all) to 5 (totally); ${ }^{4} \mathrm{P}$ : pos change indicates patients' opinions on positive change after evaluation/diagnosis, scale I (not at all) to 5 (totally); ${ }^{5}$ One person in the ADHD group had two persons answering the questionnaire, a parent and the partner. *Significantly higher than the 'No ADHD/ASD/TS' group, 95\% Cl.

Abbreviations: ADHD, attention-deficit/hyperactivity disorder; ASD, autistic spectrum disorder; Cl, confidence interval; MR, mental retardation; NDT, Neuropsychiatric Diagnosis Team; S/A abuse, substance and/or alcohol abuse; SOs, significant others; TS, Tourette's syndrome.

the responders can be seen in Tables 1 and 2, respectively. Data on the responding SOs are shown in Table 3.

There was no significant difference in age or follow-up time between responders and nonresponders on the whole or in the ASD group. Responders with no new diagnosis tended to be significantly older than nonresponders, and nonresponders with ADHD tended to be those more recently evaluated. The responder group contained more women and more patients with mental retardation. The most common pre-evaluation diagnostic groups (affective disorders and developmental disorders) appeared in the same frequency among the responders and the nonresponders.

It must be noted that not every patient or SO had responded to every question. For example, very few correct GAF self-evaluations had been made so this measure was not meaningful to include in the study. Since the TS group contained only two persons, their follow-up data were not included in the tables.

\section{Changes from baseline to follow-up}

Changes in housing, maintenance, medication, and contacts with health care and habilitation services in the three diagnostic groups can be seen in Tables 4-6.

The greatest changes were an increase in the rate of independent living in the ASD group, an increase in the number of persons of ADHD receiving treatment with psychotropic medication, and an increase in the number of persons receiving habilitation services in both groups. There was a decrease in the number of persons in contact with health care in the group with 'no new diagnosis'. In all three groups, the number of persons maintaining themselves on work (full-time or part-time) was small, with no significant changes from baseline to follow-up.

\section{Patients' satisfaction with life circumstances and with the diagnostic procedure}

Patients' opinions on their housing, way of maintenance, work, treatment contacts, and their overall satisfaction with their life situation, as well as their opinions on the diagnostic procedure and its consequences, were collected only at follow-up. The mean values of their scores, as well as the response frequency for the different questions, can be seen in Tables 4-6.

Patients with 'no new diagnosis', $\mathrm{n}=33$, response frequency $42 \%$ (Table 4 )

This group had in common that they had been referred (or had referred themselves) to the NDT on account of a suspicion of ADHD, ASD, or TS. Persons with extensive psychiatric histories as well as a few individuals with only minor impairments are included in the group. Except for the decrease in health care contacts, no significant changes were reported by this group. The group is used as a comparison group for the patients' opinions collected with the follow-up questionnaires. 
Table 4 Responders with no ADHD/ASD/TS diagnosis $(n=33)$

\begin{tabular}{|c|c|c|}
\hline & Baseline & Follow-up \\
\hline Independent living (\%) & $26(78.8)$ & $23(69.7)$ \\
\hline $\begin{array}{l}\text { Satisfaction with dwelling (mean) } \\
n=32\end{array}$ & - & 3.78 \\
\hline Work income (\%) & $8(24.3)$ & $10(30.3)$ \\
\hline $\begin{array}{l}\text { Satisfaction with income (mean) } \\
n=33\end{array}$ & - & 2.85 \\
\hline $\begin{array}{l}\text { Satisfaction with daily occupation } \\
(\text { mean })^{\prime} n=29\end{array}$ & - & 2.97 \\
\hline $\begin{array}{l}\text { Treated in adult psychiatry } \\
\text { before evaluation (\%) }\end{array}$ & $27(81.8)$ & - \\
\hline $\begin{array}{l}\text { No contact with psychiatry } \\
\text { before evaluation (\%) }\end{array}$ & $3(9.1)$ & - \\
\hline Medication (\%) & $14(42.4)$ & $15(45.4)$ \\
\hline Health care (\%) & $28(84.8)$ & $20(60.6)$ \\
\hline Habilitation service contact (\%) & I (3.0) & 0 \\
\hline $\begin{array}{l}\text { Satisfaction with treatment/support } \\
(\text { mean })^{1} n=21\end{array}$ & - & 3.19 \\
\hline $\begin{array}{l}\text { Usefulness of evaluation (mean) } \\
n=28\end{array}$ & - & 2.82 \\
\hline $\begin{array}{l}\text { Professionalism of evaluation (mean)' } \\
n=29\end{array}$ & - & 3.69 \\
\hline Positive change in life (mean) ${ }^{1} n=32$ & - & 2.06 \\
\hline $\begin{array}{l}\text { Negative change in life (mean) } \\
n=25\end{array}$ & - & 1.40 \\
\hline $\begin{array}{l}\text { Change in social relations (mean) } \\
n=32\end{array}$ & - & 3.50 \\
\hline $\begin{array}{l}\text { Did you get help as expected (mean)' } \\
n=29\end{array}$ & - & 2.31 \\
\hline $\begin{array}{l}\text { Satisfaction with present situation (mean)' } \\
n=29\end{array}$ & - & 3.00 \\
\hline
\end{tabular}

Notes: 'Scale $\mathrm{I}-5$ ( $\mathrm{I}=$ not at all, $2=$ not very much, $3=$ moderately/no change, $4=$ to a great extent, $5=$ totally)

Abbreviations: ADHD, attention-deficit/hyperactivity disorder; ASD, autistic spectrum disorder; TS, Tourette's syndrome.

Patients with ADHD, $\mathrm{n}=45$, response frequency $54 \%$ (Table 5 )

No significant changes had occurred regarding independent living, work income, or health care contacts. Fewer than onethird of the ADHD patients had income from work, while almost three-quarters lived independently. At baseline, 15 persons received pharmacological treatment, while at follow-up, 28 persons were treated. Several new treatments were with stimulants (11 patients). Eight persons had contacts with habilitation services at follow-up compared to 4 at baseline.

ADHD patients rated their satisfaction with housing, income, work situation, and treatment contacts as very slightly above 3 (moderate), with no significant differences compared to ASD patients or patients with 'no new diagnosis'.

Patients with ADHD gave high ratings (above 4 on a scale from 1 to 5) for correctness of diagnosis, usefulness of the evaluation, and professionalism of the team. Usefulness of the evaluation was, not surprisingly, given significantly
Table 5 Responders with ADHD $(n=45)$

\begin{tabular}{|c|c|c|}
\hline & Baseline & Follow-up \\
\hline Independent living (\%) & $33(73.3)$ & $33(73.3)$ \\
\hline Satisfaction with dwelling (mean) ${ }^{\prime} n=4$ I & - & 3.98 \\
\hline Work income (\%) & $12(26.6)$ & $13(28.9)$ \\
\hline $\begin{array}{l}\text { Satisfaction with income (mean) } \\
n=40\end{array}$ & - & 3.28 \\
\hline $\begin{array}{l}\text { Satisfaction with daily occupation (mean)' } \\
n=4 \text { I }\end{array}$ & - & 3.39 \\
\hline $\begin{array}{l}\text { Treated in adult psychiatry before } \\
\text { evaluation (\%) }\end{array}$ & $34(75.6)$ & - \\
\hline $\begin{array}{l}\text { No contact with psychiatry before } \\
\text { evaluation (\%) }\end{array}$ & $4(8.9)$ & - \\
\hline Medication (\%) & $15(33.3)$ & $28(62.2)$ \\
\hline Stimulant medication (\%) & $0(0)$ & II (24.4) \\
\hline Health care (\%) & $31(68.9)$ & $32(7 I . I)$ \\
\hline Habilitation service contact (\%) & $4(8.9)$ & $8(17.8)$ \\
\hline $\begin{array}{l}\text { Satisfaction with treatment/support (mean)' } \\
\mathrm{n}=35\end{array}$ & - & 3.40 \\
\hline Correct diagnosis (mean) ${ }^{\prime} n=4$ I & - & 4.27 \\
\hline $\begin{array}{l}\text { Usefulness of evaluation (mean)' } \\
n=44\end{array}$ & - & $4.1 I^{*}$ \\
\hline $\begin{array}{l}\text { Professionalism of evaluation (mean)' } \\
n=44\end{array}$ & - & $4.23 *$ \\
\hline Positive change in life (mean) $)^{\prime} n=44$ & - & $3.14^{*}$ \\
\hline Negative change in life (mean) $)^{\prime} n=39$ & - & 1.74 \\
\hline Change in social relations (mean) ${ }^{\prime} n=43$ & - & 3.51 \\
\hline $\begin{array}{l}\text { Did you get help as expected (mean)' } \\
n=40\end{array}$ & - & 2.70 \\
\hline $\begin{array}{l}\text { Satisfaction with present situation (mean)' } \\
n=43\end{array}$ & - & $3.58^{*}$ \\
\hline
\end{tabular}

Notes: 'Scale I-5 ( I = not at all, 2 = not very much, $3=$ moderately/no change, 4 = to a great extent, $5=$ totally $)$. $*$ Significant difference $(95 \% \mathrm{Cl})$ compared to the 'no new diagnosis' group.

Abbreviation: ADHD, attention-deficit/hyperactivity disorder.

higher ratings by patients receiving an ADHD diagnosis than by patients receiving 'no new diagnosis'. ADHD patients also rated the positive change resulting from the evaluation significantly higher than the 'no new diagnosis' group, while they did not differ significantly from the latter group regarding their opinion on whether they had received the help they had hoped for. They rated their satisfaction with their life situation as a whole at slightly above 3 (moderate).

\section{Responders with ASD, $n=4 I$, response frequency 66\% (Table 6)}

Regarding maintenance, medication, and health care contacts, almost no changes had occurred in the ASD group. The rate of independent living had increased from one-third to just over one-half of the individuals $(P<0.05)$, even if this rate is still lower than in any of the other groups. The number of persons with contact with habilitation services had more than doubled. 
Table 6 Responders with ASD $(n=4 I)$

\begin{tabular}{|c|c|c|}
\hline & Baseline & Follow-up \\
\hline Independent living (\%) & $14(34.1)$ & $22(53.7)$ \\
\hline Satisfaction with dwelling (mean) ${ }^{1} n=39$ & - & 4.36 \\
\hline Work income (\%) & $7(17.1)$ & $7(17.1)$ \\
\hline Satisfaction with income (mean) $n=35$ & - & $3.66^{*}$ \\
\hline $\begin{array}{l}\text { Satisfaction with daily occupation (mean)' } \\
\mathrm{n}=35\end{array}$ & - & 3.43 \\
\hline $\begin{array}{l}\text { Treated in adult psychiatry before } \\
\text { evaluation (\%) }\end{array}$ & $28(68.3)$ & - \\
\hline $\begin{array}{l}\text { No contact with psychiatry before } \\
\text { evaluation (\%) }\end{array}$ & $7(17.1)$ & - \\
\hline Medication (\%) & $21(5 \mid .2)$ & $20(48.8)$ \\
\hline Health care (\%) & $30(73.2)$ & $29(70.7)$ \\
\hline Habilitation service contact (\%) & $9(22.0)$ & $20(48.8)$ \\
\hline $\begin{array}{l}\text { Satisfaction with treatment/support (mean) } \\
n=29\end{array}$ & - & 3.66 \\
\hline Correct diagnosis (mean) ${ }^{\prime} n=34$ & - & 3.85 \\
\hline Usefulness of evaluation (mean) $n=40$ & - & $4.05^{*}$ \\
\hline Professionalism of evaluation (mean) ${ }^{\prime} n=4$ I & - & 4.10 \\
\hline Positive change in life (mean)' $n=40$ & - & $3.15^{*}$ \\
\hline Negative change in life (mean) $)^{\prime} n=38$ & - & 1.68 \\
\hline Change in social relations (mean) ${ }^{1} n=38$ & - & 3.21 \\
\hline Did you get help as expected (mean) $)^{\prime} n=39$ & - & $3.21^{*}$ \\
\hline $\begin{array}{l}\text { Satisfaction with present situation (mean)' } \\
n=39\end{array}$ & - & $3.62 *$ \\
\hline
\end{tabular}

Notes: 'Scale I-5 (I = not at all/much worse, $2=$ not very much/worse, $3=$ moderately/no change, $4=$ to a great extent/better, $5=$ totally/much better) *Significant difference $(95 \% \mathrm{Cl})$ compared to the 'no new diagnosis' group. Abbreviations: ASD, autistic spectrum disorder.

ASD patients rated their satisfaction with housing, income, occupation, and treatment higher than any of the other two groups, but the difference was significant only for income in comparison with the 'no new diagnosis' group.
ASD patients rated usefulness and positive effects of the evaluation significantly higher than the 'no new diagnosis' group. The ASD group, not unexpectedly, had the lowest rating for positive change in social contacts at follow-up. ASD patients felt significantly more positive than the "no new diagnosis' group for having been given the help they hoped to get, even if the mean value for this rating in the ASD group was only slightly above 3 . They rated their satisfaction with their life situation significantly higher than the "no new diagnosis' group.

\section{Responders with TS, $\mathrm{n}=2$, response frequency $100 \%$}

The two male TS patients rated all opinion questions at 3 or above. On the scale of $1-5$, they gave ratings of 4 or above for their satisfaction with housing, income, and work as well as for correctness of diagnosis, usefulness, and professionalism of the evaluation.

\section{SO (Table 7)}

Of the $86 \mathrm{SO}$ questionnaires mailed, 61 (70.5\%) were returned. One was excluded since it did not contain answers to the questions. In one case, two SOs responded (Figure 1). Of the total number of patients included, we were thus able to get responses from SOs in $27 \%$. The SOs of ADHD patients were parents (59\%) or partners (34\%), while the SOs of ASD patients were primarily parents $(80 \%)$ and only in one case (5\%) a partner: This reflects that of all the patients with ASD, $93 \%$ had always been single, while this was the case for $49 \%$ of the ADHD group.

Table 7 SOs' opinions, numbered as questions in questionnaire

\begin{tabular}{|c|c|c|c|}
\hline Diagnosis & No ADHD/ASD/TS $(n=I I)$ & $\operatorname{ADHD}(n=28)$ & $\operatorname{ASD}(n=20)$ \\
\hline 2. Accuracy of diagnosis (n) & $2.90(10)$ & $4.24(29)^{*}$ & $4.50(20)^{*}$ \\
\hline 3. Usefulness of evaluation ( $n$ ) & $2.40(10)$ & $3.69(29)^{*}$ & $4.20(20)^{*}$ \\
\hline 4. Quality (n) & $3.50(10)$ & $3.93(29)^{\dagger}$ & $4.80(20)^{*, t}$ \\
\hline 8. Change in life situation (n) & $2.44(9)$ & $3.74(27)^{*}$ & $4.10(20)^{*}$ \\
\hline 9. Change in social relations ( $\mathrm{n}$ ) & $3.11(9)$ & $3.71(28)$ & $4.00(19)^{*}$ \\
\hline II. Occupation adequate (n) & $2.38(8)$ & $3.08(26)$ & $3.25(20)$ \\
\hline 13. Housing adequate (n) & $3.27(\mathrm{II})$ & $4.24(29)$ & $3.80(20)$ \\
\hline 14. Change pract needs ( $n$ ) & $2.70(10)$ & $2.86(28)$ & $2.55(20)$ \\
\hline 15. Change emot needs (n) & $2.80(10)$ & $3.07(27)$ & $2.55(20)$ \\
\hline 16. SO burden, practical (n) & $3.36(11)$ & $2.59(27)$ & $2.60(20)$ \\
\hline I7. SO burden emotional (n) & $3.73(\mathrm{II})$ & $3.07(28)$ & $3.20(20)$ \\
\hline 18. Change service cont (n) & $3.09(11)$ & $3.52(27)$ & $4.00(19)^{*}$ \\
\hline 19. Adequate help (n) & $2.73(\mathrm{II})$ & $3.08(25)$ & $3.40(20)$ \\
\hline GAF - 2 weeks $(n)$ & $61.6(9)$ & 7I.I (23) & $67.4(19)$ \\
\hline GAF - year (n) & $58.7(9)$ & $69.8(24)$ & $63.2(19)$ \\
\hline
\end{tabular}

Notes: Family burden, practical: parents $(n=42): 2.83$; partners $(n=10): 2.70$. Family burden, emotional: parents $(n=43): 3.33$; partners $(n=10): 3.20$. Scale $I-5(I=$ not at all/much worse, $2=$ not very much/worse, $3=$ moderately/no change, $4=$ to a great extent/better, $5=$ totally/much better). Questions $8,9,14,15$, and 18 : change after evaluation/diagnosis. *Significant difference $(95 \% \mathrm{Cl})$ to the 'No ADHD/ASD/TS' group; ‘'Significant difference $(95 \% \mathrm{Cl})$ between ADHD and ASD group.

Abbreviations: ADHD, attention-deficit/hyperactivity disorder; ASD, autistic spectrum disorder; Cl, confidence interval; GAF, Global Assessment of Functioning scale; SO, significant others; TS, Tourette's syndrome. 
The opinions of the SOs are shown in Table 7. The SOs of the ASD and ADHD groups rated the accuracy of diagnosis, usefulness of the assessment, and positive change in life situation significantly higher than the SOs of the "no new diagnosis' group. The SOs of the ASD group gave the quality of the examination a significantly higher rating than the SOs of the ADHD and 'no new diagnosis' group, and they noted a more positive change in the patients' relations and contacts with services.

There were no significant differences across the diagnostic groups in family burden. The SOs indicated the emotional burden inflicted by the patient's disorder as heavier than the practical burden. GAF ratings were lowest in the 'no new diagnosis' group and highest in the ADHD group.

\section{Discussion}

In many psychiatric clinics, specialized diagnostic services for adults with suspected ADHD or ASD have been organized, since it has been assumed that diagnosing these disorders, persisting from childhood, in adults is generally beneficial. However, the patients' and their SOs' experiences of receiving a diagnosis of ADHD or ASD in adulthood has, with one exception $^{32}$ where patients' opinions on access to adequate services was measured, not been investigated. This study attempted to do this in a large group of patients, but encountered certain difficulties.

The study comprised a group of 231 consecutive patients, of whom $19(8 \%)$ had earlier diagnoses of ASD, ADHD equivalents, or TS, who were neuropsychiatrically examined and diagnosed by the first two authors, and who where assigned either a developmental disorder diagnosis (ADHD, ASD, or TS) or no such diagnosis. The latter group was chosen as control group since the aims of the study were to examine the consequences of getting a developmental disorder diagnosis in adulthood versus not getting one of these diagnostic labels. The individuals in each diagnostic group were not matched with individuals in the 'no new diagnosis' group. In addition, the 'no new diagnosis' group by definition was qualitatively different from the groups that met diagnostic criteria. It is thus questionable if the groups can be compared. However, it is difficult to find a comparable group since there are no waiting lists with undiagnosed patients certain to get a diagnosis later.

The questionnaire, which was mailed to the participants, was constructed for this study and thus not validated since the questions were either about patients' opinions or about facts such as medication, contact with services, or housing.
The response frequency at follow-up after 12-44 months among the patients and SOs in this study was low, from $42 \%$ in the 'no new diagnosis' group to $66 \%$ in the ASD group. One reason for this may have been that the questionnaire was difficult to comprehend or demanded too much sustained attention. Psychiatric patients and particularly those with ADHD, a diagnosis associated with impairments in sustained attention, persistence, and purposefulness, may find a 32-item questionnaire too demanding. A similar low-response frequency (53\% of ADHD patients and 75\% of ASD patients) was encountered in an earlier, smaller, Swedish follow-up study, ${ }^{32}$ even though the questionnaire in that study was considerably shorter. A questionnaire with more open-ended qualitative questions may yield interesting and unexpected answers, but, in this patient group with serious executive problems, may not raise the response rate. Personal interviews of patients and SOs may be a method that would gain a higher number of responders but is very resource consuming. In this study, the SOs were contacted only after written permission was given by the patient to do so, and the number of responding SOs was thus even lower than the number of responding patients.

The low-response frequencies, together with the rather broad questions on opinions in the questionnaires, make this study more of a contribution to a methodological discussion and an illustration of the difficulties encountered in the follow-up of diagnostic services than an argument for or against diagnosing persisting developmental disorders in adulthood. It is a common assumption that receiving a wellsubstantiated diagnosis is beneficial for the individual, but this assumption may not be so easy to affirm. It is essential to evaluate psychiatric treatments and services, but in the case of diagnostic services, methods for evaluation are scarce. Rather than systematic research, the data generated by this study represent an attempt at and proposal for clinical audit.

The follow-up times varied from 1 to almost 4 years, and it can be argued that this is a short time to follow up the effects on the life circumstances of an adult of getting a diagnostic label on a life-long disorder which has not recently stricken but pervasively affected the person's life since early childhood. One able and verbal adult with ASD has described in her self-biography that it may be a time-consuming process to adjust to a diagnosis with a connotation of serious disability. ${ }^{38}$ In addition, of course many factors other than a diagnostic label may affect a person's life circumstances.

One of the most conspicuous changes reported by the patients was the increase in independent living in the ASD group; however, the mean age of the ASD group was lower 
than that of the other two groups, and the mean age of the persons having moved to independent living at follow-up (24.2 years) was significantly lower than the mean age of those not having moved (31.5 years) in this group. The moves may thus in many cases have been motivated by the persons getting older and moving away from their parents. The change in medication - more stimulant medication in the ADHD group - was expected, since there is evidence for the efficacy of this treatment in ADHD in adults ${ }^{39}$ and stimulant treatment is becoming increasingly common in adult psychiatry. It was also expected that more patients in the ADHD and, especially, the ASD group would get habilitation services after getting diagnoses.

In the ADHD, as well as the ASD group, patients gave positive ratings for correctness of diagnosis, which probably was an effect of the time taken to arrive at diagnostic consensus including the patient. ADHD and ASD patients and their SOs gave high ratings for usefulness of the evaluation as such, as well as for professionalism during the evaluation. The rating of usefulness was not correlated to whether neuropsychological testing or collateral interview had been performed.

The patients' ratings of any positive changes in their lives resulting from the evaluation were moderate. Rather surprisingly, ADHD and ASD patients found that the evaluation had brought more of a negative change than the 'no new diagnosis' group, although this difference was nonsignificant. The stigma attached to most psychiatric diagnoses may be one reason for this experience. Only the ASD group reported any extent of getting the help they had expected.

Across the three groups, those respondents $(n=30)$ who had income from work were significantly more satisfied with their income, their occupation, and with their total life situation than those who had other means of maintenance (most commonly sick leave or pension). To the contrary, persons living independently $(n=78)$ did not rate their satisfaction with their housing or with their life situation at follow-up significantly higher than those who had other types of accommodation. The data on alcohol and/or substance dependence/abuse are merely anamnestic, but it is an intriguing side finding that patients with ASD appeared to have very low rates. Possibly, the use of alcohol or street drugs is more uncommon in ASD patients than in the general population, as has been shown for nicotine consumption. $^{40}$

The SOs of the two diagnosed groups rated their emotional and practical burden as moderate. Since the study did not include a healthy comparison group, it can only be speculated that similar ratings made by SOs of normal adults would be significantly lower.

From this study, it cannot be concluded whether or not it is clearly beneficial, in the person's or SO's own opinions or as reflected in changes in life circumstances in the first years after diagnosis, for an adult individual to get a diagnosis of ADHD or ASD. The satisfaction with postdiagnostic services was highest in the ASD group. However, the diagnostic procedure with a detailed developmental history, involvement of SO, assessment by two professionals (psychiatrist and psychologist), and time taken to, if possible, arrive at diagnostic consensus with the patient appeared to have been appreciated by ADHD and ASD patients. Moreover, the group that did not get any new diagnosis had a favorable opinion of the procedure, which can be used for diagnosing other disorders than ADHD, ASD, or TS, as well as for getting a more complete picture and better understanding of many psychiatric patients, regardless of suspected or established diagnosis.

\section{Acknowledgments}

This study was financed by grants from the Ellen and Henrik Sjöbring Foundation, Region Skåne, and Göteborg University. Our sincere thanks to all the patients who have taken time and effort to participate in this study.

\section{Disclosure}

The authors report no conflicts of interest in this work.

\section{References}

1. Hill JC, Schoender EP. Age-dependent decline of attention deficit hyperactivity disorder. Am J Psychiatry. 1996;153(9):1143-1146.

2. Rasmussen P, Gillberg C. Natural outcome of ADHD with developmental coordination disorder at age 22 years: a controlled, longitudinal, community-based study. J Am Acad Child Adolesc Psychiatry. 2000; 39(11):1424-1431.

3. Gittelman R, Mannuzza S, Shenker R, Bonagura N. Hyperactive boys almost grown up. I. Psychiatric status. Arch Gen Psychiatry. 1985; 42(10):937-947.

4. Faraone SV, Biederman J, Spencer T, et al. Attention-deficit/hyperactivity disorders in adults: an overview. Biol Psychiatry. 2000;48(1):9-20.

5. Biederman J, Petty CR, Fried R, et al. Stability of executive function deficits into young adult years: a prospective longitudinal follow-up study of grown up males with ADHD. Acta Psychiatr Scand. 2007; 116(2):129-136.

6. Dowson JH. Characteristics of adults with attention-deficit/hyperactivity disorder and past conduct disorder. Acta Psychiatr Scand. 2008;117(4): 299-305.

7. Davidson MA. ADHD in adults: a review of the literature. JAtten Disord. 2008;11(6):628-641.

8. Able SL, Johnston JA, Adler LA, Swindle RW. Functional and psychosocial impairment in adults with undiagnosed ADHD. Psychol Med. 2007;37(1):97-107.

9. Nylander L, Holmqvist M, Gustafson L, Gillberg C. ADHD in adult psychiatry. Minimum rates and clinical presentation in general psychiatry outpatients. Nord J Psychiatry. 2009;63(1):64-71. 
10. Biederman J. Impact of comorbidity in adults with attentiondeficit/hyperactivity disorder. J Clin Psychiatry. 2004;65 Suppl 3:3-7.

11. McGough JJ, Smalley SL, McCracken JT, et al. Psychiatric comorbidity in adult attention deficit hyperactivity disorder: findings from multiplex families. Am J Psychiatry. 2005;162(9):1621-1627.

12. Newcorn JH. Managing ADHD and comorbidities in adults. $J$ Clin Psychiatry. 2009;70(2):e40.

13. Rydén E, Thase ME, Stråht D, Åberg-Wistedt A, Bejerot S, Landén M. A history of childhood attention-deficit hyperactivity disorder (ADHD) impacts clinical outcome in adult bipolar patients regardless of current ADHD. Acta Psychiatr Scand. 2009;120(3):239-246.

14. Billstedt E, Gillberg IC, Gillberg C. Autism after adolescence: population-based 13- to 22-year follow-up study of 120 individuals with autism diagnosed in childhood. J Autism Dev Disord. 2005;35(3): 351-360. Erratum in J Autism Dev Disord. 2007;37(9):1822.

15. Billstedt E, Gillberg IC, Gillberg C. Autism in adults: symptom patterns and early childhood predictors. Use of the DISCO in a community sample followed from childhood. J Child Psychol Psychiatry. 2007; 48(11):1102-1110.

16. Cederlund M, Hagberg B, Billstedt E, Gillberg IC, Gillberg C. Asperger syndrome and autism: a comparative longitudinal follow-up study more than 5 years after original diagnosis. J Autism Dev Disord. 2008; 38(1):72-85.

17. Nordin V, Gillberg C. The long-term course of autistic disorders: update on follow-up studies. Acta Psychiatr Scand. 1998;97(2): $99-108$.

18. Howlin P. Outcome in high-functioning adults with autism with and without early language delays: implications for the differentiation between autism and Asperger syndrome. J Autism Dev Disord. 2003; 33(1):3-13.

19. Howlin P, Goode S, Hutton J, Rutter M. Adult outcome for children with autism. J Child Psychol Psychiatry. 2004;45(2):212-229.

20. Farley MA, McMahon WM, Fombonne E, et al. Twenty-year outcome for individuals with autism and average or near-average cognitive abilities. Autism Res. 2009;2(2):109-118.

21. Wing L, Shah A. Catatonia in autistic spectrum disorders. Br J Psychiatry. 2000;176:357-362.

22. Mouridsen SE, Rich B, Isager T. Psychiatric disorders in adults diagnosed as children with atypical autism. A case control study. J Neural Transm. 2008;115(1):135-138.

23. Hutton J, Goode S, Murphy M, Le Couteur A, Rutter M. New-onset psychiatric disorders in individuals with autism. Autism. 2008;12(4): 373-390.

24. Ghaziuddin M, Zafar S. Psychiatric comorbidity of adults with autism spectrum disorders. Clin Neuropsychiatry. 2008;5:9-12.

25. American Psychiatric Association. Diagnostic and Statistical Manual of Mental Disorders. 4th ed (DSM-IV). Washington, DC: American Psychiatric Association; 2000.
26. Nylander L, Gillberg C. Screening for autism spectrum disorders in adult psychiatric out-patients: a preliminary report. Acta Psychiatr Scand. 2001;103(6):428-434.

27. Nydén A, Myrén K-J, Gillberg C. Long-term psychosocial and health economy consequences of ADHD, autism, and reading-writing disorder: a prospective service evaluation project. J Atten Disord. 2008; 12(2):141-148.

28. Mugno D, Ruta L, D’Arrigo VG, Mazzone L. Impairment of quality of life in parents of children and adolescents with pervasive developmental disorders. Health Qual Life Outcomes. 2007;5:22.

29. Coghill D, Soutullo C, d'Aubuisson C, et al. Impact of attentiondeficit/hyperactivity disorder on the patient and family: results from a European survey. Child Adolesc Psychiatry Ment Health. 2008;2(1):31.

30. Phelps KW, McCammon SL, Wuensch KL, Golden JA. Enrichment, stress, and growth from parenting an individual with an autism spectrum disorder. J Intellect Dev Disabil. 2009;34(2):133-141.

31. Steinhausen H-C. The heterogeneity of causes and courses of attentiondeficit/hyperactivity disorder. Acta Psychiatr Scand. 2009;120(5): 392-399.

32. Brar A, Flyckt L. Vuxna med neuropsykiatrisk diagnos får inte tillräcklig hjälp. Läkartidningen. 2006;103(19):1516-1522.

33. Canu WH, Newman ML, Morrow TL, Pope DL. Social appraisal of adult ADHD: stigma and influences of the beholder's Big Five personality traits. J Atten Disord. 2008;11(6):700-710.

34. Huws JC, Jones RS. Diagnosis, disclosure, and having autism: An interpretative phenomenological analysis of the perceptions of young people with autism. J Intellect Dev Disabil. 2008;33(2):99-107.

35. Shtayermman O. An exploratory study of the stigma associated with a diagnosis of Asperger's syndrome: the mental health impact on the adolescents and young adults diagnosed with a disability with a social nature. J Hum Behav Soc Environ. 2009;19(3):298-313.

36. Gillberg C, Gillberg C, Råstam M, Wentz E. The Asperger syndrome (and high-functioning autism) diagnostic interview (ASDI): a preliminary study of a new structured clinical interview. Autism. 2001; 5(1):57-66.

37. Lunds Universitet. Neuropsychiatric Diagnostic Team follow-up questionnaires. Available from: http://www.med.lu.se/klinvetlund/ geriatrisk_psykiatri/publikationer/neuropsychiatric_diagnostic_team. Accessed 2010 Sep 27.

38. Norrö G. Aspergers Syndrom - Har Jag Verkligen Det? Stockholm, Sweden: Intermedia Books; 2008.

39. Bejerot S, Rydén EM, Arlinde CM. Two years outcome of central stimulant medication in adult attention deficit hyperactivity disorder a prospective study. J Clin Psychiatry. 2010 Jun 1. [Epub ahead of print].

40. Bejerot S, Nylander L. Low prevalence of smoking in patients with autism spectrum disorders. Psychiatry Res. 2003;119(1-2):177-182.
Clinical Audit

\section{Publish your work in this journal}

Clinical Audit is an international, peer-reviewed, open access journal focusing on the processes and outcomes of clinical audit in any area of healthcare. All aspects of patient care are addressed within the journal and practitioners from all disciplines are invited to submit their work. Areas covered include: Publication of audits; How an audit has changed practice; Submit your manuscript here: http://www.dovepress.com/clinical-audit-journal

\section{Dovepress}

Practical tips on how to do audits and to avoid pitfalls; How audits have changed patient care; Calls and justifications for new audits. The manuscript management system is completely online and includes a very quick and fair peer-review system, which is all easy to use. Visit http://www.dovepress. com/testimonials.php to read real quotes from published authors. 